\title{
Aerial Surveys and Geographic Information in Modern China
}

\author{
Hajime YAMAMOTO \\ Ritsumeikan University, College of Letters, hajime67@fc.ritsumei.ac.jp
}

Keywords: Aerial surveys, Geographic information, Modern China, Nanjing

\section{Abstract:}

Today when online satellite images are just a click away, access to geographic information showing the latest images of the globe has dramatically expanded, and historico-geographic research based on such information is flourishing. However, in the study of Chinese history, historical research employing GIS or similar technologies is still in its infancy, since "historical" geographic information with a high degree of precision are lacking. From within the ambit of Chinese geographic information, this report specifically highlights aerial surveys effected during the Republic of China era. To start, we review the history of domestic aerial surveys during R. O. C. period. Then, focusing on Nanjing as an example, we proceed to introduce maps that were actually created based on aerial surveys.

Chinese aerial surveys date back to around 1930. At the Nationalist Party's General Assembly in 1929, partisans proposed for the need for aerial surveys. In 1930, the "Aerial Photography and Survey Research Team" was formed within the General Land Survey Department at General Staff Headquarters (National Army of the Republic of China). Consequently, foreign technicians were invited to provide relevant education/training. In June 1931, China's pioneer initiative in aerial photography took place in Zhejiang province. The aim of aerial surveys in those early days was to create maps for military purposes. Between 1932 and 1939, topographic maps of fortifications located in areas such as the Jiangnan district were prepared. Further, starting from around the same period until the Sino-Japanese War, land registry maps based on aerial surveys were also produced. After the Sino-Japanese War ended, the above-mentioned directorate handed over responsibility for aerial surveys to the Naval General Staff. However, in 1949 the Chinese Communist Party confiscated the maps theretofore produced.

Although the aerial photographs and the geographic information produced therefrom during the R. O. C. era were seized by the People's Republic of China, in actuality, some had previously been transferred to Taiwan. The topographic maps of the Nanjing metropolitan area (一萬分一南京城廂附近圖), based on aerial surveys and drawn in 1932, are currently archived at Academia Historica in Taipei. Comprising a total of 16 sheets, these maps were drawn on a scale of 1:10,000 by the General Land Survey Department.

Similarly, other maps (各省分幅地形圖) produced by the General Land Survey Department, comprising a total of 56 sheets and partly detailing Nanjing, are now in the possession of Academia Sinica in Taipei. There was no information about photographing or making in these maps. But almost the same maps were archived at Library of Congress in Washington D. C. According to those maps at LC, based on aerial photographs taken and surveys conducted in 1933, these topographic maps (1:10,000 scale) were completed in 1936.

The examples introduced above are topographic maps based on aerial photography. However, starting in 1937, land registry maps were also created. Detailing the outskirts of Nanjing (1:1,000 scale) and comprising a total of 121 sheets, they are now archived at Academia Historica. While the land registry maps were produced in 1937, supplementary surveys were effected following the Sino-Japanese War in 1947.

Since the geographic information based on aerial surveys during the R. O. C. era in China were precise, they can serve as a source of manifold information. This report only delved into information developed by the Government of 
the R. O. C., but it is becoming evident that U. S. Armed Forces and Japan also produced geographic information of their own based on aerial surveys. If the comprehensive panorama captured by all three protagonists can be illuminated, further advances in Chinese historico-geographic studies employing geographic information will be forthcoming.
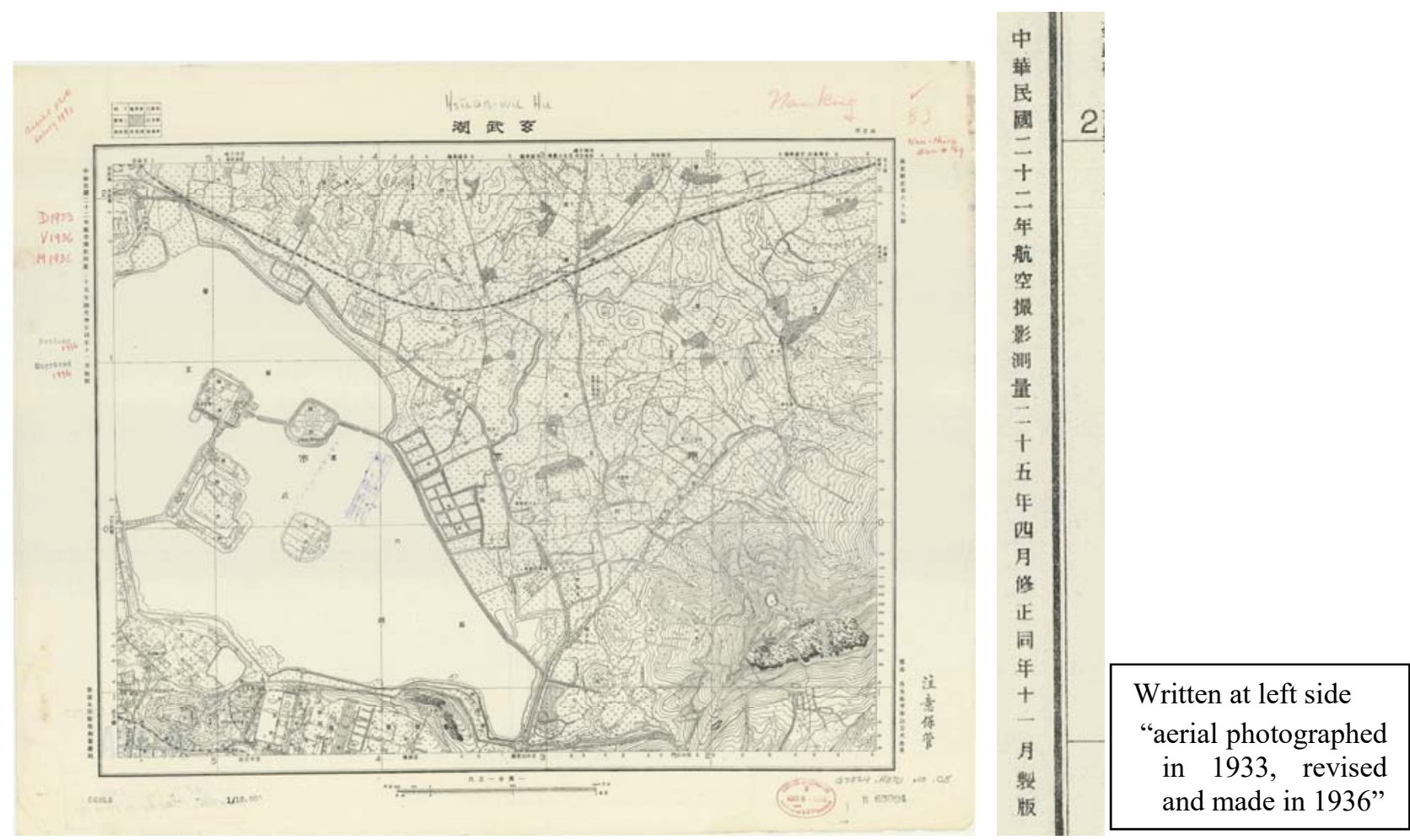

Figure 1. Example of topographic maps made in 1930s

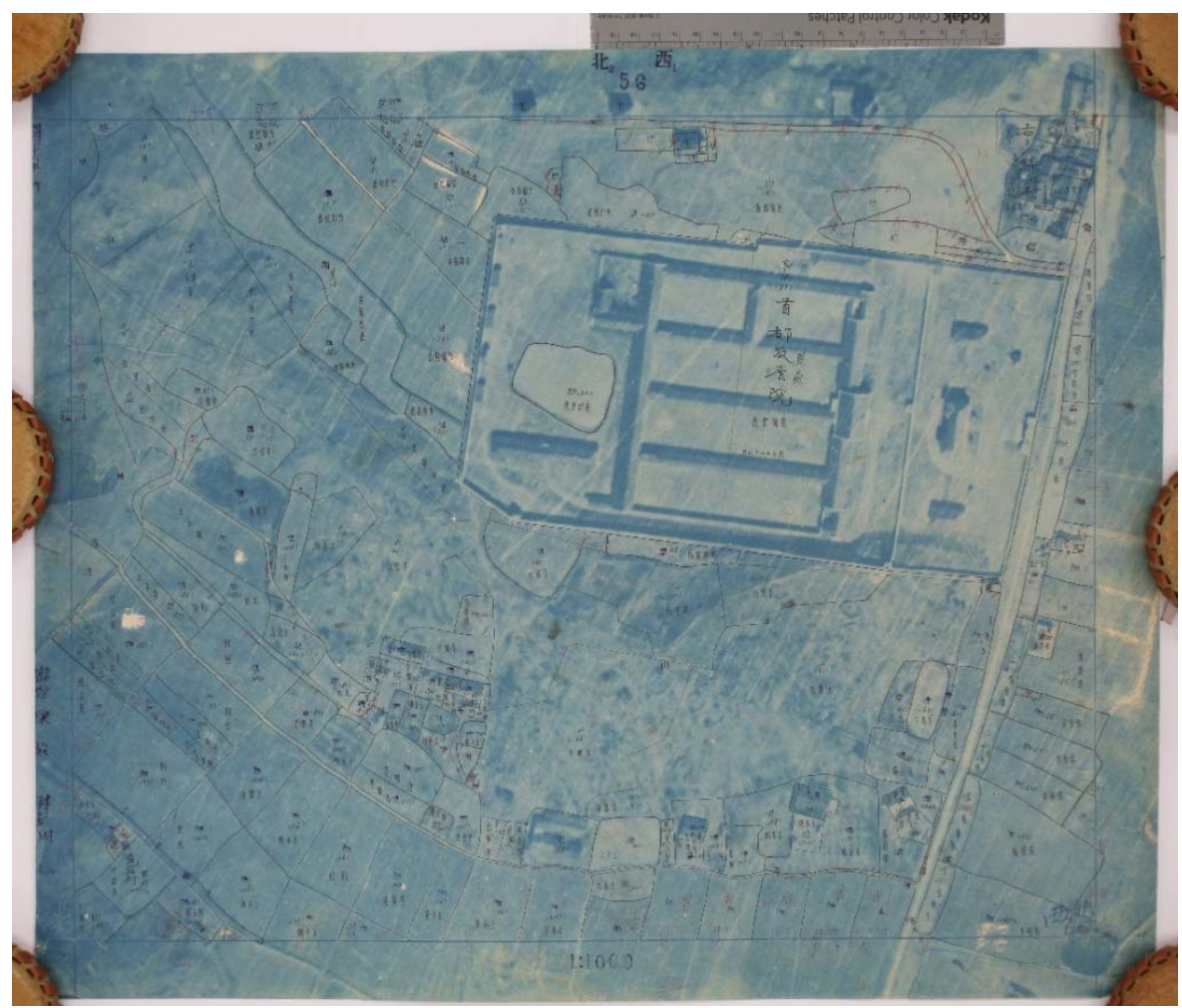

Figure 2. Example of land registry maps by aerial survey in 1937. 